\title{
Higher capecitabine AUC in elderly patients with advanced colorectal cancer (SWOGS0030)
}

\author{
S G Louie ${ }^{*}, 1,2$, B Ely ${ }^{2}$, H-J Lenz ${ }^{1,2}$, KS Albain ${ }^{4}$, C Gotay ${ }^{5}$, D Coleman ${ }^{6}$, D Raghavan ${ }^{1,2,7}$, A F Shields ${ }^{8}$, P J Gold ${ }^{9}$ \\ and C D Blanke 5,10 \\ ${ }^{1}$ Department of Pharmacy, University of Southern California, Los Angeles, CA, USA; ${ }^{2}$ Department of Oncology, Norris \\ Comprehensive Cancer Center, Los Angeles, CA, USA; ${ }^{3}$ SWOG Statistical Center, Seattle, WA, USA; ${ }^{4}$ Loyola University \\ Chicago/Cardinal Bernardin Cancer Center, Maywood, IL, USA; ${ }^{5}$ University of British Columbia, Vancouver, British Columbia, \\ Canada; ${ }^{6}$ Cancer Research Center of Hawaii, Honolulu, HI, USA; ${ }^{7}$ Carolinas Medical Center/Levine Cancer Institute, Charlotte, NC, \\ USA; ${ }^{8}$ Karmanos Cancer Institute/Wayne State University, Detroit, MI, USA; ${ }^{9}$ Swedish Cancer Institute, Seattle, WA, USA and \\ ${ }^{10}$ Knight Cancer Institute and SWOG, Portland, OR, USA
}

Background: The aging process is accompanied by physiological changes including reduced glomerular filtration and hepatic function, as well as changes in gastric secretions. To investigate what effect would aging have on the disposition of capecitabine and its metabolites, the pharmacokinetics between patients $\geqslant 70$ years and $<60$ years were compared in SWOG0030.

Methods: Twenty-nine unresectable colorectal cancer patients were stratified to either $\geqslant 70$ or $<60$ years of age, where the disposition of capecitabine and its metabolites were compared.

Results: Notable increase in capecitabine area under the curve (AUC) was accompanied by reduction in capecitabine clearance in $\geqslant 70$ years patients $(P<0.05)$. No difference in $5^{\prime}$-deoxy-5-fluorocytidine, $5^{\prime}$-deoxy-5-fluorouridine (DFUR), and 5-fluorouracil (5FU) AUCs between the two age groups, suggesting that carboxylesterase and cytidine deaminase (CDA) activity was similar between the two age groups. These results suggest that metabolic enzymes involved in converting capecitabine metabolites are not altered by age. An elevation in capecitabine $\mathrm{Cmax}$ and reduction in clearance was seen in females, where capecitabine AUC was $40.3 \%$ higher in women. Elevation of DFUR Cmax $(45 \%)$ and AUC (46\%) $(P<0.05)$ was also noted, suggesting that CDA activity may be higher in females.

Conclusion: Increases in capecitabine $\mathrm{Cmax}$ and AUC was observed in patients $\geqslant 70$ years when compared with younger patients who were $>60$ years.

Colorectal cancer is the third most common neoplasm in the United States, where adenocarcinomas are far and away the most common histology therein. Historically, the combination of 5-fluorouracil (5FU) and leucovorin (LV) has been the standard first-line treatment for metastatic colorectal cancer, resulting in a median survival of 11.5 months and an overall response rate of $23 \%$ in treatment naive patients (Hoff et al, 1998, 2001). The addition of irinotecan (CPT11) and oxaliplatin to $5 \mathrm{FU} / \mathrm{LV}$ regimen substantially increased mean survival to 16-20 months (Douillard et al, 2000; Saltz et al, 2000). Even more encouraging are results arising from the addition of new biological agents, such as bevacizumab, cetuximab, and panitumumab; using various combinations of these drugs achieves median overall survival extending beyond 2 years for patients with metastatic disease (Hurwitz et al, 2005; Wadhawan et al, 2009).

These changes continue to be built upon a foundation of a fluoropyridimine-based regimen, in particular 5FU. Other efforts to improve on 5FU include the substitution of capecitabine, an oral pro-drug of $5 \mathrm{FU}$, which has emerged as an important component in the treatment of metastatic colorectal cancer. Capecitabinecontaining regimens are the first-line therapy of choice in patients

*Correspondence: Dr SG Louie; E-mail: slouie@usc.edu

Received 8 November 2012; revised 7 August 2013; accepted 9 August 2013; published online 10 September 2013

(c) 2013 Cancer Research UK. All rights reserved 0007-0920/13 
with metastatic colorectal cancer when single-agent fluoropyrimidine is preferred (Iqbal and Lenz, 2004).

After oral absorption, capecitabine is rapidly converted into $5^{\prime}$-deoxy-5-fluorocytidine (DFCR) via hepatic carboxylesterase. DFCR is further metabolised to $5^{\prime}$-deoxy-5-fluorouridine (DFUR), a reaction that is catalysed by cytidine deaminase (CDA), a ubiquitous enzyme found in high levels in the liver, plasma, and tumour tissue (Somasekaram et al, 1999). Thymidine phosphorylase catalyses the conversion of DFUR into 5FU, where the expression level of this enzyme is 3 to 10 times higher in tumour cells as compared with levels found in normal tissues (Miwa et al, 1999).

Radioactive-labelled capecitabine studies have shown that $99.5 \%$ of radioactivity is recovered from urine (Judson et al, 1999), indicating that renal excretion is the major elimination pathway for capecitabine and its metabolites. As renal status declines with age, older patients theoretically may accumulate capecitabine as compared with younger patients receiving the same dosage. Advancement of age has also been linked to increased oxidative stress, mitochondrial dysfunction, telomere shortening, and gene expression of various metabolic enzymes (McLean and Le Couteur, 2004). These changes can also lead to alterations in pharmacokinetics through changes in drug absorption, distribution, metabolism, and elimination (McLean and Le Couteur, 2004).

In this study, the impact of age on the pharmacokinetics of capecitabine and its metabolites was evaluated. This was accomplished using a validated multiplex LC-MS assay that is able to quantify all of the analytes in one assay. Comparisons between patients who were $\geqslant 70$ years of age and patients who were younger than 60 years old were made. In addition, the clinical outcome in relation to drug disposition was also evaluated in the management of advanced colorectal cancer in elderly patients $(\geqslant 70$ years $)$.

\section{MATERIALS AND METHODS}

Study subjects. Twenty-nine eligible patients and controls were recruited into the SWOGS0030 (ClinicalTrials.gov Identifier: NCT00049335). In addition, the clinical outcome in relation to drug disposition was also evaluated in the management of advanced colorectal cancer in elderly patients $(\geqslant 70$ years $)$ in comparison with those $<60$ years old. The institutional review boards at participating institutions approved the study protocol. Patients were informed of the investigational nature of the study and provided written informed consent before enrolment in accordance with institutional and federal guidelines. After patients were confirmed to have unresectable metastatic or recurrent colorectal cancer, they were stratified by age, either $\geqslant 70$ years or younger than 60 years.

Other inclusion criteria include possessing measurable disease, serum creatinine, SGOT, SGPT, and bilirubin values of no more than two-fold higher than institutional upper limit of normal. In addition, the estimated renal creatinine clearance $(\mathrm{CrCl})$ had to be $>50 \mathrm{ml} \mathrm{min}^{-1}$. Patients were required to have an absolute granulocyte count of equal or greater than 1500 cells $\mu \mathrm{l}^{-1}$ and platelet count no $<100000$ cells $\mu \mathrm{l}^{-1}$. Patients should not have received prior chemotherapy for advanced cancer; however, prior adjuvant chemotherapy was allowed if recurrence happened $>12$ months after the last adjuvant treatment. Patients must have recovered from the effects of prior surgery or radiation. Patients were to be excluded if they have known brain metastases, or if they were pregnant or nursing, HIV positive or suffering from other life-threatening intercurrent medical disorders.

Study design. Each participant was administered capecitabine $1000 \mathrm{mg} \mathrm{m}^{-2}$ BID PO with food from days 1 through 14. Cycles were repeated every 21 days to a maximum of 18 cycles. Pharmacokinetic study of capecitabine was conducted on day 1 , when peripheral blood was withdrawn at pre-dose time, $0.5,1$, $1.5,2,4,6$, and $24 \mathrm{~h}$ after a witness dose of capecitabine oral administration. Patient samples were collected in tetrahydrouridine containing tubes and the samples were centrifuged and plasma supernatant was collected and stored in $-80^{\circ} \mathrm{C}$ freezer until further analysis.

Estimating glomerular filtration. Renal status was calculated using two estimated glomerular filtration rate (eGFR) equations. The Cockroft-Gault equation used is Equation 1 and the modification of diet in renal disease (MDRD) is Equation 2:

$$
\begin{aligned}
\mathrm{eGFR}= & {[(140-\text { Age }) \times \mathrm{IBW}] /(72 \times \text { Serum Creatinine }) } \\
& \times(0.85 \text { if female }) \\
\mathrm{eGFR}= & 186 \times \text { Serum Creatinine- } 1.154 \times \text { Age- } 0.203 \\
& \times[1.212 \text { if Black }] \times[0.742 \text { if female }]
\end{aligned}
$$

Determination of plasma concentrations of capecitabine and its metabolites. To quantify capecitabine and its metabolites, plasma samples were processed using a modified method as described by Salvador et al (2006). In brief, $500 \mu \mathrm{l}$ of plasma samples were spiked with $20 \mu \mathrm{l}$ of $400 \mathrm{ng} \mathrm{ml}^{-1}$ zidovudine (AZT) dissolved in $80 \% \mathrm{MeOH}$ as internal standard. To these samples, $10 \mu \mathrm{l} 1 \mathrm{M}$ citric acid and $400 \mu \mathrm{l}$ of $18 \mathrm{~mm}$ ammonia acetate were added and the $\mathrm{pH}$ adjusted to 5.0. After vigorous mixing, the samples were centrifuged at 5000 r.p.m. for $5 \mathrm{~min}$ at $4{ }^{\circ} \mathrm{C}$. The clarified supernatant was applied onto Atoll XWP cartridge (Interchim, Montluçon, France), which was pre-conditioned sequentially with $1 \mathrm{ml} \mathrm{H}_{2} \mathrm{O}, 1 \mathrm{ml} \mathrm{MeOH}$, and $500 \mu \mathrm{l} 18 \mathrm{~mm}$ ammonia acetate with $\mathrm{pH}$ adjusted to 5. After application onto the cartridge, the sample was washed with $500 \mu \mathrm{l}$ of $10 \%(\mathrm{v} / \mathrm{v}) \mathrm{MeOH}$ in $18 \mathrm{~mm}$ ammonia acetate with $\mathrm{pH}$ adjusted to 5.0. Analytes were eluted using two $1 \mathrm{ml}$ aliquots of $\mathrm{MeOH}$. The collected eluents were evaporated to dryness using a steady flow of filtered dry air and then reconstituted with $150 \mu \mathrm{l}$ of $50 \% \mathrm{MeOH}$. An aliquot of $20 \mu \mathrm{l}$ of reconstituted samples was injected into LCMS.

Capecitabine, its metabolites (DFCR, DFUR, and 5-FU, respectively), and internal standard (zidovudine, AZT) were separated on a Zorbax Bonus-RP column (Agilent, Palo Alto, CA, USA), $4.6 \mathrm{~mm} \times 150 \mathrm{~mm}, 5 \mu$. The mobile phase consisted of $50 \%$ water and $50 \%$ methanol $(\mathrm{v} / \mathrm{v})$ for the first $1 \mathrm{~min}$ where the methanol was increased from $50 \%$ to $95 \%$ methanol over the next $4 \mathrm{~min}$, maintained for an additional $5 \mathrm{~min}$, and the percentage of methanol returned to baseline over the next $8 \mathrm{~min}$. The flow rate was set at $0.25 \mathrm{ml} \mathrm{min}^{-1}$.

Capecitabine and its metabolites were quantified using a Sciex API3000 mass spectrometer (MS; Sciex AB, Foster City, CA, USA). The MS was operated in the negative mode using a turbo ion spray source. Quantification of capecitabine, DFCR, DFUR, 5FU, and AZT used multiple reaction monitoring where mass to transition ions were $358.4 \rightarrow 154.3,245.0 \rightarrow 129.2$, $244.1 \rightarrow 127.8,129.2 \rightarrow 41.8$, and $266.2 \rightarrow 223.2$, respectively. The retention times were $16.2,8.2$, 7.5, 7.0, and $12.5 \mathrm{~min}$ for capecitabine, DFCR, DFUR, 5FU, and AZT, respectively.

Plasma capecitabine was linear from 1 to $5000 \mathrm{ng} \mathrm{ml}^{-1}$ with correlation coefficients of at least 0.99 . The DFCR and DFUR concentrations were linear in the range of $100-40000 \mathrm{ng} \mathrm{ml}^{-1}$, whereas $5 \mathrm{FU}$ concentrations were linear in the range of $10-5000 \mathrm{ng} \mathrm{ml}^{-1}$. The average inter-day coefficient of variation (CV) was $6 \%, 6 \%, 7 \%$, and $10 \%$ for each of the intraday capecitabine, DFCR, DFUR, and 5FU, respectively.

Pharmacokinetic modelling. Pharmacokinetic analysis for capecitabine, DFCR, DFUR, and 5FU was performed initially 
using the non-compartment (model independent) method provided by WINNONLIN 4.0 software (Pharsight, Sunnyvale, CA, USA). Total drug exposure was estimated by area under the curve (AUC) methods, which was determined by the trapezoidal rule. Half-life $\left(\mathrm{T}_{1 / 2}\right)$, total clearance $(\mathrm{CL} / \mathrm{F})$, volume of distribution $(\mathrm{Vd} /$ $\mathrm{F})$, and AUC were the primary PK parameters estimated and used for further calculations of secondary PK parameters, such as elimination constant (Kel).

Statistical analysis. Differences in demographics/clinical characteristics and analyte pharmacokinetic parameters between groups (patients 70 years or older $v s$ patients younger than 60 years old) were compared using Mann-Whitney $t$-test, unpaired $t$-test or $\chi^{2}$ where appropriate. The significance level was assumed to be 0.05 . Analyses were performed using GraphPad Prism version 4.0 for Windows (GraphPad Software, San Diego, CA, USA).

\section{RESULTS}

Patient characteristics. A total of 29 patients were enrolled in the study. The demographic data between the two age groups are summarised in Table 1 . Five were in the $<60$ years group, with an average age of $55.0 \pm 3.1$. There were 24 patients who were $\geqslant 70$ years with an average age of $76.5 \pm 4.6$ years, where the mean age in the younger cohort was $55.0 \pm 3.1$ years. There were more females in the $\geqslant 70$ years group $(n=8)$ when compared with $<60$ years group $(n=1)$. Body surface area (BSA) normalised renal $\mathrm{CrCl}$ between the $<60$ years group mean was $98.9 \pm 16.3 \mathrm{ml} \mathrm{min}^{-1}$ per $1.73 \mathrm{~m}^{2}$, which was significantly higher than the $\geqslant 70$ years group $\left(71.04 \pm 15.24 \mathrm{ml} \mathrm{min}^{-1}\right.$ per $\left.1.73 \mathrm{~m}^{2}, P=0.015\right)$. However, baseline renal function calculated using MDRDs did not detect statistically significant differences between the two age groups, suggesting that $\mathrm{CrCl}$ may be impacted by a difference in ethnicity when estimating GFR.

Pharmacokinetics of capecitabine and its metabolites. The noncompartmental $\mathrm{PK}$ analysis for capecitabine and its metabolites is summarised in Table 2. In Figure 2A, a lower AUC capecitabine was found in patients who were $<60$ years old when compared with those $\geqslant 70$ years old $\left(4098 \pm 2852\right.$ vs $10238 \pm 6355 \mathrm{~h} \mathrm{ng} \mathrm{ml}^{-1}$, $P=0.045)$. This corresponds to a total capecitabine clearance $(\mathrm{Cl} / \mathrm{F})$ of $507.8 \pm 585.6 \mathrm{l} \mathrm{h} \mathrm{m}^{-2}$ in the $<60$ years group (Figure $2 \mathrm{~B}$ ), which was significantly higher than in patients $\geqslant 70$ years old $\left(146.1 \pm 107.21 \mathrm{~h}^{-1} \mathrm{~m}^{-2}, \quad P=0.035\right)$. The mean Cmax was $3035 \pm 2316 \mathrm{ng} \mathrm{ml}^{-1}$ for those $<60$ years old, and $9105 \pm 7303 \mathrm{ng}$ $\mathrm{ml}^{-1}$ (Figure 1A) for patients $\geqslant 70$ years old, demonstrating a statistically significant difference $(P=0.026)$. In patients $<60$ years old, the apparent capecitabine $\mathrm{Vd} / \mathrm{F}$ was $582.2 \pm 720.81 \mathrm{~m}^{-2}$,

\begin{tabular}{|c|c|c|c|}
\hline & $<60$ Years & $\geqslant 70$ Years & $\boldsymbol{P}$-value \\
\hline No. patients & 5 & 24 & \\
\hline No. females (\%) & $1(20 \%)$ & $8(33 \%)$ & \\
\hline Mean age (years) & $55.0 \pm 3.1$ & $76.5 \pm 4.6$ & $<0.001$ \\
\hline Mean weight $(\mathrm{kg})$ & $82.2 \pm 15.5$ & $78.03 \pm 12.93$ & NS \\
\hline Mean BSA $\left(\mathrm{m}^{2}\right)$ & $1.95 \pm 0.15$ & $1.87 \pm 0.17$ & NS \\
\hline $\mathrm{CrCL}\left(\mathrm{ml} \mathrm{min}{ }^{-1}\right.$ per $\left.1.73 \mathrm{~m}^{2}\right)$ & $98.9 \pm 16.3$ & $71.04 \pm 15.24$ & 0.015 \\
\hline $\operatorname{MDRD}\left(\mathrm{ml} \mathrm{min}{ }^{-1}\right.$ per $\left.1.73 \mathrm{~m}^{2}\right)$ & $85.00 \pm 7.40$ & $81.92 \pm 20.44$ & NS \\
\hline \multicolumn{4}{|c|}{$\begin{array}{l}\text { Abbreviations: } \mathrm{BSA}=\text { body surface area; } \mathrm{CrCl}=\text { creatinine clearance; } \mathrm{MDRD}=\text { modified } \\
\text { diet for renal disease; } \mathrm{NS}=\text { not significant. } \mathrm{A} \text { total of } 29 \text { patients were evaluated in this } \\
\text { study, where } 5 \text { patients were in the }<60 \text { years of age and } 24 \text { in the } \geqslant 70 \text { years of age. The } \\
\text { values are mean } \pm \text { s.d. }\end{array}$} \\
\hline
\end{tabular}

which was significantly higher than $150.0 \pm 104.1 \mathrm{~m}^{-2}$ in patients $\geqslant 70$ years $(P=0.046$, Table 1$)$. No statistical significance was achieved between the two groups with regards to capecitabine halflife and Tmax.

When the metabolites of capecitabine were evaluated, no significant differences in AUCs for DFCR, DFUR, and 5FU between patients $<60$ and $\geqslant 70$ years old were detected (Figure 1). Similarly, elimination constants for DFCR, DFUR, and 5FU were not marked different between the two age groups.

Difference of males and females on capecitabine. The demographics between the females and males are summarised in Table 3, where there was no significant difference between the two sexes except for BSA and capecitabine Cmax and Kel. In addition, DFUR Cmax was also statistically different between males and females. As expected, the BSA for males was significantly larger than that of the females in this cohort. In addition, the capecitabine Cmax levels for females were two-fold higher than those achieved in males $(P=0.028)$, which corresponded to higher Kel for females as compared with males. Renal clearance, however, was not different between the two sexes, which was estimated using $\mathrm{CrCl}$ and $\mathrm{MDRD}$ equations when adjusted for BSA.

Despite similarities in renal clearance, notable differences in capecitabine pharmacokinetics were revealed between the two sexes (Table 3). Females had a higher capecitabine and DFUR Cmax, but not DFCR and 5FU when compared with the males; however, the $5 \mathrm{FU}$ half-life was significantly longer in males $(1.21 \pm 0.58 \mathrm{~h})$ when compared with females $(0.78 \pm 0.20 \mathrm{~h}$; $P<0.05)$.

Table 2. Pharmacokinetic parameters for capecitabine, DFCR, DFUR, and $5 \mathrm{FU}$ in patients $<60$ and $>70$ years of age

\begin{tabular}{|c|c|c|c|}
\hline & $<60$ Years & $\geqslant 70$ Years & $\boldsymbol{P}$-value \\
\hline \multicolumn{4}{|c|}{ Capecitabine PK } \\
\hline $\mathrm{Cmax}\left(\mathrm{ng} \mathrm{ml} \mathrm{l}^{-1}\right)$ & $3035 \pm 2316$ & $9105 \pm 7303$ & $0.026^{*}$ \\
\hline $\mathrm{T}_{1 / 2}(\mathrm{~h})$ & $0.74 \pm 0.17$ & $0.78 \pm 0.32$ & 0.709 \\
\hline $\operatorname{Kel}\left(h^{-1}\right)$ & $0.71 \pm 0.40$ & $0.95 \pm 0.46$ & 0.275 \\
\hline$A \cup C\left(h \operatorname{s~ml}^{-1}\right)$ & $4098 \pm 2852$ & $10238 \pm 6355$ & $0.045^{\star}$ \\
\hline $\mathrm{CL} / \mathrm{F}\left(\mathrm{lh} \mathrm{m}^{-2}\right)$ & $507.78 \pm 585.57$ & $146.10 \pm 107.22$ & $0.035^{\star}$ \\
\hline $\mathrm{Vd} / \mathrm{F}\left(\mathrm{Im}^{-2}\right)$ & $582.24 \pm 720.84$ & $150.01 \pm 104.06$ & $0.046^{*}$ \\
\hline
\end{tabular}

\section{DFCR PK}

\begin{tabular}{|l|c|c|c|}
\hline $\left.\mathrm{Cmax}(\mathrm{ng} \mathrm{m})^{-1}\right)$ & $7168 \pm 6699$ & $6361 \pm 3711$ & 0.705 \\
$\mathrm{~T}_{1 / 2}(\mathrm{~h})$ & $0.850 \pm 0.130$ & $0.899 \pm 0.536$ & 0.312 \\
$\mathrm{Kel}\left(\mathrm{h}^{-1}\right)$ & $0.831 \pm 0.131$ & $0.976 \pm 0.422$ & 0.462 \\
$\left.\mathrm{AUC}(\mathrm{h} \mathrm{ng} \mathrm{ml})^{-1}\right)$ & $11766 \pm 9648$ & $12461 \pm 7406$ & 0.977 \\
\hline
\end{tabular}

DFUR PK

\begin{tabular}{|l|c|c|l|}
\hline Cmax $\left(\mathrm{ng} \mathrm{m}^{-1}\right)$ & $10252 \pm 5546$ & $10373 \pm 5901$ & 0.967 \\
$\mathrm{~T}_{1 / 2}(\mathrm{~h})$ & $0.936 \pm 0.287$ & $1.094 \pm 0.759$ & 0.795 \\
$\mathrm{Kel}\left(\mathrm{h}^{-1}\right)$ & $0.793 \pm 0.223$ & $0.820 \pm 0.339$ & 0.867 \\
$\mathrm{AUC}\left(\mathrm{h} \mathrm{ng} \mathrm{ml} l^{-1}\right)$ & $20737 \pm 12257$ & $19852 \pm 9382$ & 0.977 \\
\hline
\end{tabular}

\begin{tabular}{|c|c|c|c|}
\hline \multicolumn{4}{|l|}{ 5FU PK } \\
\hline $\mathrm{Cmax}\left(\mathrm{ng} \mathrm{ml^{-1 }}\right)$ & $2688 \pm 3138$ & $2074 \pm 1569$ & 0.665 \\
\hline $\mathrm{T}_{1 / 2}(\mathrm{~h})$ & $1.171 \pm 0.764$ & $1.060 \pm 0.490$ & 0.795 \\
\hline $\operatorname{Kel}\left(h^{-1}\right)$ & $0.752 \pm 0.343$ & $0.789 \pm 0.353$ & 0.795 \\
\hline AUC (hng ml ${ }^{-1}$ ) & $4986 \pm 5786$ & $3677 \pm 1861$ & 0.840 \\
\hline
\end{tabular}

Abbreviations: $\mathrm{AUC}=$ area under the curve; $\mathrm{Cmax}=$ maximum concentration; $\mathrm{CL} / \mathrm{F}=$ total clearance; $\quad \mathrm{DFCR}=5^{\prime}$-deoxy-5-fluorocytidine; $\quad \mathrm{DFUR}=5^{\prime}$-deoxy-5-fluorouridine; $5 \mathrm{FU}=5$-fluorouracil; Kel = elimination constant; $\mathrm{PK}=$ pharmacokinetic; $\mathrm{T}_{1 / 2}=$ half-life; $\mathrm{Vd} / \mathrm{F}=$ volume of distribution. Statistical comparisons used with either unpaired $t$-test or Mann-Whitney test where $\left(^{*}\right) P<0.05$ is denote. 

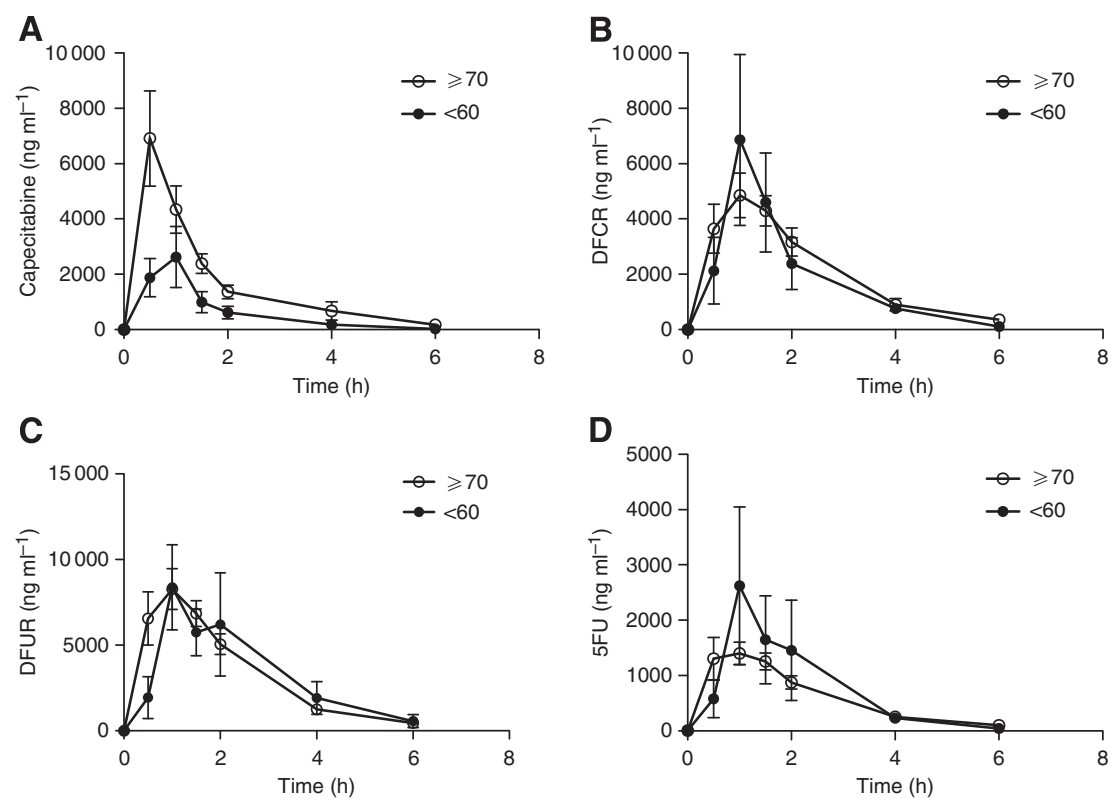

Figure 1. Concentration vs time curves of capecitabine and its metabolites (B-D). Capecitabine $\mathrm{Cmax}$ in the $>70$ years group was significantly higher than patients in $<60$ years group $(P>0.05)(\mathbf{A})$. The concentration vs time curves for each of the capecitabine metabolites such as $5^{\prime}$-deoxy5-fluorocytidine (DFCR; B), 5'-deoxy-5-fluorouridine (DFUR; C), and 5-fluorouracil (5FU; D) compared between the subjects who were $<60$ and $>70$ years of age. Statistical comparisons used with unpaired t-test where $\left.{ }^{*}\right) P<0.05$ is denote.
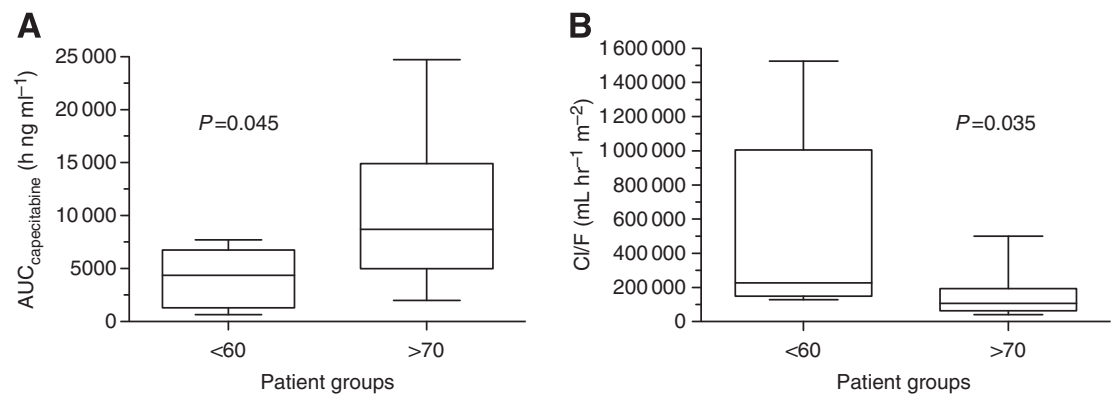

Figure 2. Comparisons of capecitabine area under the curve (AUC; $\mathbf{A}$ ) and clearance (B) between the two age groups, where statistic difference is seen with for both capecitabine AUC and its clearance.

\section{DISCUSSION}

Physiological change accompanies the aging process, which in turn can alter drug disposition. Decreases in gastric acid secretion (Feldman, 1997; Feldman and Cryer, 1998), reduction in gastric emptying, and slower colonic transit times (Wiley, 2002), which can alter orally administered agents, have been previously described in elderly patients. These physiological changes may alter Tmax and the maximum concentration (Cmax) achieved following an oral administration. These changes may be further compounded by polypharmacy and multiple intercurrent disorders in the elderly.

Increased capecitabine Cmax and AUC (Figures 1A and 2A) were observed in patients $\geqslant 70$ years, which corresponded to lower capecitabine clearance (Figure 2B, Table 1). A three-fold increase in capecitabine Cmax was detected in the $\geqslant 70$ years group when compared with control subjects. In addition, patients who were $\geqslant 70$ years old had a capecitabine AUC that was two-fold higher than patients $<60$ years old.

However, our findings may be affected by the imbalance in the number of females between the two age groups. When the disposition of capecitabine and its metabolites were also compared between the two sexes, demographics and physiological data were similar between the two groups except for BSA. Only one (1 out of $5,20 \%)$ female in was in the $<60$ years group, whereas eight females ( 8 out of $24,33.3 \%$ ) were enrolled in the $\geqslant 70$ years group.
Cmax for capecitabine and DFUR were statistically higher in females as compared with males. However, no difference in capecitabine AUC was detected between the two sexes. Females had an elevated DFUR Cmax (45\%) and AUC (46\%), suggesting that CDA activity may be higher in females as compared with males. A significantly higher DFUR AUC was found in females; however, this did not lead to a difference in circulating 5FU. One study reported a correlation between DFUR AUC with toxicities in animals, but these findings were not affirmed in humans (Shindoh et al, 2006).

No studies were found evaluating the impact of reduced gastric acid on capecitabine absorption. However, co-administration of aluminum hydroxide (Maalox) with capecitabine resulted in a moderate increase in the Cmax and AUC of capecitabine and DFCR, where $10-31 \%$ increase was observed. Despite the elevation of capecitabine and DFCR, the changes mediated by aluminum hydroxide did not reach statistical significance (Reigner et al, 1999). As aluminum hydroxide was only administered once in this study, it is difficult to determine what effects persistent neutralisation of gastric acid may have on capecitabine and DFCR disposition. It is conceivable that reduced gastric acid production in the elderly may provide a similar scenario, where the reduction in acid would reduce the breakdown of capecitabine. Enhanced capecitabine absorption may be further facilitated by slower intestinal transit time; however, studies are necessary to verify this hypothesis. 
Table 3. Difference in pharmacokinetics of capecitabine and its metabolites in male and female subjects

\begin{tabular}{|c|c|c|c|}
\hline & Female & Male & $P$-value \\
\hline No. patients & 9 & 20 & \\
\hline Age (years) & $74.44 \pm 8.93$ & $72.10 \pm 9.64$ & 0.541 \\
\hline Weight (kg) & $74.03 \pm 11.78$ & $80.87 \pm 13.52$ & 0.203 \\
\hline $\mathrm{BSA}\left(\mathrm{m}^{2}\right)$ & $1.76 \pm 0.15$ & $1.95 \pm 0.14$ & 0.003 \\
\hline $\mathrm{CrCL}\left(\mathrm{ml} \mathrm{min}{ }^{-1}\right.$ per $\left.1.73 \mathrm{~m}^{2}\right)$ & $77.61 \pm 13.82$ & $64.51 \pm 14.39$ & 0.035 \\
\hline $\operatorname{MDRD}\left(\mathrm{ml} \mathrm{min}{ }^{-1}\right.$ per $\left.1.73 \mathrm{~m}^{2}\right)$ & $73.41 \pm 14.09$ & $79.45 \pm 18.43$ & 0.391 \\
\hline \multicolumn{4}{|l|}{ Capecitabine PK } \\
\hline $\begin{array}{l}\text { Cmax }\left(\mathrm{ng} \mathrm{ml} \mathrm{l}^{-1}\right) \\
\mathrm{T}_{1 / 2}(\mathrm{~h}) \\
\mathrm{Kel}\left(\mathrm{h}^{-1}\right) \\
\text { AUC }\left(\mathrm{h} \mathrm{ng} \mathrm{ml^{-1 }}\right) \\
\text { CLtotal/F }\left(\mathrm{l} \mathrm{h}^{-1} \mathrm{~m}^{-2}\right) \\
\operatorname{Vd} / \mathrm{F}\left(\mathrm{m}^{-2}\right)\end{array}$ & 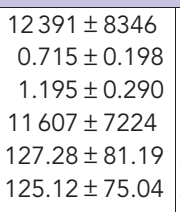 & $\begin{array}{c}6109 \pm 5612 \\
0.793 \pm 0.339 \\
0.781 \pm 0.461 \\
8087 \pm 5727 \\
244.98 \pm 327.56 \\
269.27 \pm 392.46\end{array}$ & $\begin{array}{l}0.028^{\star} \\
0.654 \\
0.020^{\star} \\
0.169 \\
0.268 \\
0.248\end{array}$ \\
\hline \multicolumn{4}{|l|}{ DFCR PK } \\
\hline $\begin{array}{l}\text { Cmax }\left(\mathrm{ng} \mathrm{m} l^{-1}\right) \\
T_{1 / 2}(h) \\
\operatorname{Kel}\left(h^{-1}\right) \\
\text { AUC }\left(h \mathrm{ng} \mathrm{ml}^{-1}\right)\end{array}$ & $\begin{array}{c}7519 \pm 3967 \\
0.737 \pm 0.216 \\
1.039 \pm 0.410 \\
14599 \pm 10408\end{array}$ & $\begin{array}{c}6041 \pm 4350 \\
0.960 \pm 0.562 \\
0.911 \pm 0.385 \\
11325 \pm 6082\end{array}$ & $\begin{array}{l}0.393 \\
0.621 \\
0.621 \\
0.525\end{array}$ \\
\hline \multicolumn{4}{|l|}{ DFUR PK } \\
\hline $\begin{array}{l}\text { Cmax }\left(\mathrm{ng} \mathrm{m} \mathrm{m}^{-1}\right) \\
\mathrm{T}_{1 / 2}(\mathrm{~h}) \\
\mathrm{Kel}\left(\mathrm{h}^{-1}\right) \\
\text { AUC }\left(\mathrm{h} \mathrm{ng} \mathrm{m}^{-1}\right)\end{array}$ & $\begin{array}{c}13212 \pm 4824 \\
0.885 \pm 0.307 \\
0.870 \pm 0.302 \\
25567 \pm 11438\end{array}$ & $\begin{array}{c}9065 \pm 5762 \\
1.148 \pm 0.811 \\
0.790 \pm 0.330 \\
17501 \pm 7875\end{array}$ & $\begin{array}{l}0.030 \star \\
0.588 \\
0.540 \\
0.045\end{array}$ \\
\hline \multicolumn{4}{|l|}{ 5FU PK } \\
\hline $\begin{array}{l}\text { Cmax }\left(\mathrm{ng} \mathrm{m}^{-1}\right) \\
T_{1 / 2}(\mathrm{~h}) \\
\mathrm{Kel}\left(\mathrm{h}^{-1}\right) \\
\left.\text { AUC (hng ml }{ }^{-1}\right)\end{array}$ & $\begin{array}{c}2575 \pm 2073 \\
0.782 \pm 0.204 \\
0.948 \pm 0.276 \\
4030 \pm 2337\end{array}$ & $\begin{array}{c}2002 \pm 1794 \\
1.212 \pm 0.581 \\
0.708 \pm 0.353 \\
3846 \pm 3050\end{array}$ & $\begin{array}{l}0.334 \\
0.041^{\star} \\
0.036^{\star} \\
0.759\end{array}$ \\
\hline \multicolumn{4}{|c|}{$\begin{array}{l}\text { Abbreviations: } \mathrm{AUC}=\text { area under the curve; } \mathrm{BSA}=\text { body surface area; } \mathrm{Cmax}=\text { maximum } \\
\text { concentration; } \mathrm{CL} / \mathrm{F}=\text { total clearance; } \mathrm{CrCl}=\mathrm{creatinine} \text { clearance; } \mathrm{DFCR}=5^{\prime} \text {-deoxy- } \\
5 \text {-fluorocytidine; } \mathrm{DFUR}=5^{\prime} \text {-deoxy-5-fluorouridine; } 5 \mathrm{FU}=5 \text {-fluorouracil; } \mathrm{Kel}=\text { elimination } \\
\text { constant; } \mathrm{MDRD}=\text { modified diet for renal disease; } \mathrm{PK}=\text { pharmacokinetic; } \mathrm{T}_{1 / 2}=\text { half-life } \\
\mathrm{Vd} / \mathrm{F}=\text { volume of distribution. Statistical comparisons used with either unpaired } t \text {-test or } \\
\text { Mann-Whitney test where }\left(^{*}\right) P<0.05 \text { is denote. }\end{array}$} \\
\hline
\end{tabular}

A two-fold increase in capecitabine AUC was detected in patients $\geqslant 70$ years, which corresponded to a reduction of total capecitabine clearance. Despite an increase in capecitabine AUC, DFCR formation (Cmax) and total levels detected was similar between the two age groups, which may suggest that carboxylesterase-mediated metabolism may be able to accommodate for the addition capecitabine. In one study, $1645 \mathrm{mg} \mathrm{m}^{-2}$ capecitabine was given twice a day, where the DFCR AUC was similar to that seen in this study and the dosage was $1000 \mathrm{mg} \mathrm{m}^{-2}$ (Ebi et al, 2005). This suggests that there is sufficient carboxylesterase activity to accommodate additional capecitabine. In addition, aging has little impact on expression and activity of carboxylesterase I and II. This was demonstrated in a study where carboxylesterase enzymatic activity derived from subjects who were 75-85 years was not significantly different from microsomes derived from children (Zhu et al, 2009).

Although differences in eGFR were found to be lower in the $\geqslant 70$ group when using the Cockcroft and Gault estimation, the eGFR was almost similar when the MDRD calculation was used. Renal dysfunction was shown not to impact capecitabine disposition (Poole et al, 2002), when patients with normal renal function were compared with subjects with mild, moderate, and severe renal dysfunction. In this study, no PK differences for capecitabine or $5 \mathrm{FU}$ were detected between the patients with normal renal function as compared with those with severe impairment (Poole et al, 2002); however, increases in DFUR AUC was observed in patients with severe renal impairment $\left(\mathrm{CrCl}<30 \mathrm{ml} \mathrm{min}^{-1}\right)$, which correlated with drug safety.

In this study, the metabolites between the two age groups were similar in terms of Cmax and AUC, with the exception of capecitabine. The impact of liver function on capecitabine pharmacokinetics has been previous evaluated in patients with liver metastases with evidence of impaired hepatic function (Twelves et al, 1999). Patients with impaired liver function $(n=13)$ were compared with 14 patients with normal liver function. Patients were stratified using a scoring system based on serum bilirubin, alkaline phosphatase, and transaminase levels. Cmax and AUC of capecitabine, DFCR, and DFUR were shown to increase in patients with liver dysfunction as compared with those in patients with normal liver function; however, none of the aforementioned differences reached statistical significance.

Volume of distribution is subject to change because of several factors. It is estimated that the blood albumin concentration is about $10 \%$ less in older people compared with younger people (Yuen, 1990), which is associated with a roughly $10 \%$ increase in the unbound fraction of drugs (Grandison and Boudinot, 2000). When age increases, the body composition changes, which might in turn affect the volume of distribution in elderly patients. Usually there is a $20-40 \%$ increase in body fat and $10-15 \%$ decrease in body water and lean muscle mass (Beaufrere and Morio, 2000). This change will theoretically increase the concentration of watersoluble drugs and prolong the elimination half-life of lipid-soluble drugs. However, the half-lives of capecitabine and its metabolites were similar between the two age groups, which suggests that volume distribution may not be different between the two groups.

Owing to the fact that PK profiles of capecitabine and its metabolites are dependent on intrinsic activities of several enzymes that participate in the three metabolic steps, the expression levels and genetic polymorphisms of the aforementioned enzymes contribute substantially to the inter-individual differences in disposition of capecitabine and its metabolites. Lu et al (1998) reported a 44 -fold difference in DPD activity in peripheral blood mononuclear cells collected from patients with breast cancer, which is consistent with the finding where Peters et al (1993) showed a 1000-fold difference in Cmax of 5FU among patients receiving protracted 5FU IV infusion. CDA is a highly polymorphic enzyme that catalyzes the conversion of DFCR to DFUR. Two non-synonymous single-nucleotide polymorphisms (SNPs), 79A $>$ C (Lys27Gln) and 208G $>$ A (Ala70Thr), have been identified in the coding region of the human CDA gene, among which, in vitro studies have shown marked reduction in CDA activity for $208 \mathrm{G}>\mathrm{A}$ variant (Yue et al, 2003) and marginal decrease in activity for $79 \mathrm{~A}>\mathrm{C}$ variant (Gilbert et al, 2006). A clinical trial aiming to evaluate correlations between CDA genotypes and gemcitabine pharmacokinetics found that the AUC of gemcitabine in patients with 208G > A genotype was five-fold higher. In addition, the clearance was only $20 \%$ in patients with 208GG genotype, indicating that 208G > A SNP was correlated with decreased enzyme activity of CDA (Sugiyama et al, 2007). Further exploration of genetic polymorphisms of the participating enzymes involved in the metabolism of capecitabine and its metabolites will help to elucidate the contributing factors that cause variations in $\mathrm{PK}$ profiles for capecitabine and its metabolites.

In summary, this study demonstrated that patients who are $\geqslant 70$ years had a higher capecitabine Cmax and AUC, where clearance was approximately $1 / 3$ the rate found in patients who are $<60$ years. However, the formation of DFCR was similar between the two groups, which is further validated by others who showed 
that carboxylesterase activity is similar over a wide range of ages and able to accommodate the additional capecitabine (Ebi et al, 2005; Zhu et al, 2009). The capecitabine Cmax was three-fold higher in the $\geqslant 70$ years group, which may be due to the overall number of females that were enrolled in this study. The difference in capecitabine Cmax in females was significantly higher than in males. As there was no significant difference in the capecitabine metabolites, DFCR, DFUR, and 5FU, the enzymes responsible for these conversions may not be sensitive to the aging process. This study also affirms that the Cmax for capecitabine and DFUR were higher in women than in males. However, there was no statistical difference found in the active moiety, 5FU. It should be noted that the number of patients in the study, in particular the $<60$ years group, may be a limitation of this study. A larger cohort may be able to better determine the full impact of age on capecitabine and its metabolites disposition. However, the data from this study suggest that standard dosage $\left(1000 \mathrm{mg} / \mathrm{m}^{2}\right)$ in patients who are $\geqslant 70$ years is safe.

\section{ACKNOWLEDGEMENTS}

This study was supported by NIH/NCI 1U10-CA85443 which is jointly funded by NCI and NIA to DR. Additional support was provided by the following PHS Cooperative Agreement grant numbers awarded by the National Cancer Institute, DHHS: CA32102, CA38926, CA35119, CA45807, CA58861, CA35178, CA45808, CA45560, CA58416, CA35176, CA67575, CA58723, CA12644, CA27057, CA35431, and CA46113. Support and assistance in this project from Dr Rosemary Yancik, National Institute of Aging and National Cancer Institute is gratefully acknowledged.

\section{REFERENCES}

Beaufrere B, Morio B (2000) Fat and protein redistribution with aging: metabolic considerations. Eur J Clin Nutr 54(Suppl 3): S48-S53.

Douillard JY, Cunningham D, Roth AD, Navarro M, James RD, Karasek P, Jandik P, Iveson T, Carmichael J, Alakl M, Gruia G, Awad L, Rougier P (2000) Irinotecan combined with fluorouracil compared with fluorouracil alone as first-line treatment for metastatic colorectal cancer: a multicentre randomised trial. Lancet 25: 1041-1047.

Ebi H, Sigeoka Y, Saeki T, Kawada K, Igarashi T, Usubuchi N, Ueda R, Sasaki Y, Minami H (2005) Pharmacokinetic and pharmacodynamic comparison of fluoropyrimidine derivatives, capecitabine and $5^{\prime}$-deoxy-5fluorouridine (5'-DFUR). Cancer Chemother Pharmacol 56: 205-211.

Feldman M (1997) The mature stomach. Still pumping out acid? JAMA 278: 681-682.

Feldman M, Cryer B (1998) Effects of age on gastric alkaline and nonparietal fluid secretion in humans. Gerontology 44: 222-227.

Gilbert JA, Salavaggione OE, Ji Y, Pelleymounter LL, Eckloff BW, Wieben ED, Ames MM, Weinshilboum RM (2006) Gemcitabine pharmacogenomics: cytidine deaminase and deoxycytidylate deaminase gene resequencing and functional genomics. Clin Cancer Res 15: 1794-1803.

Grandison MK, Boudinot FD (2000) Age-related changes in protein binding of drugs: implications for therapy. Clin Pharmacokinet 38: 271-290.

Hoff PM, Ansari R, Batist G, Cox J, Kocha W, Kuperminc M, Maroun J, Walde D, Weaver C, Harrison E, Burger HU, Osterwalder B, Wong AO, Wong R (2001) Comparison of oral capecitabine versus intravenous fluorouracil plus leucovorin as first-line treatment in 605 patients with metastatic colorectal cancer: results of a randomized phase III study. J Clin Oncol 19(8): 2282-2292.

Hoff PM, Pazdur R, Benner SE, Canetta R (1998) UFT and leucovorin: a review of its clinical development and therapeutic potential in the oral treatment of cancer. Anticancer Drugs 9: 479-490.

Hurwitz HI, Fehrenbacher L, Hainsworth JD, Heim W, Berlin J, Holmgren E, Hambleton J, Novotny WF, Kabbinavar F. Bevacizumab in combination with fluorouracil and leucovorin: an active regimen for first-line metastatic colorectal cancer. J Clin Oncol (2005) 23: 3502-3508.
Iqbal S, Lenz HJ (2004) Capecitabine: the new generation of fluoropyrimidines in colorectal cancer. Expert Rev Anticancer Ther 4: 947-955.

Judson IR, Beale PJ, Trigo JM, Aherne W, Crompton T, Jones D, Bush E, Reigner B (1999) A human capecitabine excretion balance and pharmacokinetic study after administration of a single oral dose of 14C-labelled drug. Investigational New Drugs 17: 49-56.

Lu Z, Zhang R, Carpenter JT, Diasio RB (1998) Decreased dihydropyrimidine dehydrogenase activity in a population of patients with breast cancer: implication for 5-fluorouracil-based chemotherapy. Clin Cancer Res 4: 325-329.

McLean AJ, Le Couteur DG (2004) Aging biology and geriatric clinical pharmacology. Pharmacol Rev 56: 163-184.

Miwa M, Ura M, Nishida M, Sawada N, Ishikawa T, Mori K, Shimma N, Umeda I, Ishitsuka H (1999) Design of a novel oral fluoropyrimidine carbamate, capecitabine, which generates 5 -fluorouracil selectively in tumours by enzymes concentrated in human liver and cancer tissue. Eur J Cancer 34: 1274-1281.

Peters GJ, Lankelma J, Kok RM, Noordhuis P, van Groeningen CJ, van der Wilt CL, Meyer S, Pinedo HM (1993) Prolonged retention of high concentrations of 5-fluorouracil in human and murine tumors as compared with plasma. Cancer Chemother Pharmacol 31: 269-276.

Poole C, Gardiner J, Twelves C, Johnston P, Harper P, Cassidy J, Monkhouse J, Banken L, Weidekamm E, Reigner B (2002) Effect of renal impairment on the pharmacokinetics and tolerability of capecitabine (Xeloda) in cancer patients. Cancer Chemother Pharmacol 49: 225-234.

Reigner B, Clive S, Cassidy J, Jodrell D, Schulz R, Goggin T, Banken L, Roos B, Utoh M, Mulligan T, Weidekam E (1999) Influence of the antacid Maalox on the pharmacokinetics of capecitabine in cancer patients. Cancer Chemother Pharmacol 43: 309-315.

Saltz LB, Cox JV, Blanke C, Rosen LS, Fehrenbacher L, Moore MJ, Maroun JA, Ackland SP, Locker PK, Pirotta N, Elfring GL, Miller LL (2000) Irinotecan plus fluorouracil and leucovorin for metastatic colorectal cancer. Irinotecan Study Group. N Engl J Med 343: 905-914.

Salvador A, Millerioux L, Renou A (2006) Simultaneous LC-MS-MS Analysis of Capecitabine and its Metabolites (5'-deoxy-5-fluorocytidine, 5'-deoxy5-fluorouridine, 5-fluorouracil) After Off-Line SPE from Human Plasma. Chromatographia 63: 609-615.

Shindoh H, Kawashima A, Shishido N, Nakano K, Kobayashi K, Horii I (2006) Relationship between AUC of 5'-DFUR and toxicity of capecitabine, fluoropyrimidine carbamate analogs, and 5-'DFUR in monkeys, mice, and rats. J Toxicological Sci 31: 265-285.

Somasekaram A, Adam Jarmuz A, Alan How A, Scott J, Navaratnam N (1999) Intracellular localization of human cytidine deaminase identification of a functional nuclear localization signal. J Biol Chem 274: 28405-28412.

Sugiyama E, Kaniwa N, Kim SR, Kikura-Hanajiri R, Hasegawa R, Maekawa K, Saito Y, Ozawa S, Sawada J, Kamatani N, Furuse J, Ishii H, Yoshida T, Ueno H, Okusaka T, Saijo N (2007) Pharmacokinetics of gemcitabine in Japanese cancer patients: the impact of a cytidine deaminase polymorphism. J Clin Oncol 25: 32-42.

Twelves C, Glynne-Jones R, Cassidy J, Schüller J, Goggin T, Roos B, Banken L, Utoh M, Weidekamm E, Reigner B (1999) Effect of hepatic dysfunction due to liver metastases on the pharmacokinetics of capecitabine and its metabolites. Clin Cancer Res 5: 1696-1702.

Wadhawan A, Stephens R, Adams R (2009) Intermittent therapy in the palliative treatment of metastatic colorectal cancer. Exp Rev Anticancer Ther 9: 125-134.

Wiley JW (2002) Aging and neural control of the GI tract: III. Senescent enteric nervous system: lessons from extraintestinal sites and nonmammalian species. Am J Physiol Gastrointest Liver Physiol 283: G1020-G1026.

Yue L, Saikawa Y, Ota K, Tanaka M, Nishimura R, Uehara T, Maeba H, Ito T, Sasaki T, Koizumi S (2003) A functional single-nucleotide polymorphism in the human cytidine deaminase gene contributing to ara-C sensitivity. Pharmacogenetics 13: 29-38.

Yuen GJ (1990) Altered pharmacokinetics in the elderly. Clin Geriatr Med 6: 257-267.

Zhu HJ, Appel DI, Jiang Y, Markowitz JS (2009) Age- and sex-related expression and activity of carboxylesterase 1 and 2 in mouse and human liver. Drug Metab Dispos 37: 1819-1825.

This work is published under the standard license to publish agreement. After 12 months the work will become freely available and the license terms will switch to a Creative Commons AttributionNonCommercial-Share Alike 3.0 Unported License. 